\title{
ATWO-POINT APPROXIMATION APPROACH TO DETERMINING AIRCRAFT AERODYNAMIC FORCE COEFFICIENTS FOR A MAXIMAL-DURATION HORIZONTAL FLIGHT
}

\author{
Andriy Viktorovich Goncharenko (iD 0000-0002-6846-9660 \\ National Aviation University, Aerospace Faculty,1, Liubomyra Huzara Avenue, \\ Kyiv, 03058, Ukraine \\ *andygoncharenco@yahoo.com
}

\begin{abstract}
This paper proposes a two-point approximation approach to determining aircraft aerodynamic force coefficients, and compares it to the traditional methods. A variational concept is used to conduct aircraft flight trials for the maximal duration of quasi-horizontal flights. The advantages of the described optimization theories are demonstrated, in terms of aviation fuel gas savings. The results of a numerical example are presented.
\end{abstract}

Keywords: aerodynamic force, aerodynamic coefficient, test, trial, aircraft, flight, maximal duration, maximal distance, horizontal flight

Type of the work: Research Article

\section{INTRODUCTION}

In numerical modelling of aircraft test flights, the model of a material particle with changeable mass can be applied [1], [2]. The desirability of aircraft flight trial alternatives can be evaluated using Subjective Analysis Theory [3], which is based upon the entropy paradigm, initiated in [4]-[6]. Such a general approach should take into consideration a working economic activity model, as in [7], and as a whole the entropy centered doctrine leads to a variety of problem solutions, such as those pointed out in studies [8]-[16].

In any case, concepts dealing with uncertainties are applicable to a wide range of research, which can be traced with the references [17]-[26]. The mathematical apparatus used in such research is enormously rich and includes both traditional calculus, for example [27], and relatively new ideas [3].

The objective of this paper is to demonstrate the advantages of a two-point approximation model for determining aerodynamic force coefficients, with the purpose of conducting extremal flight trial flights of aircraft for the maximal duration of a quasi-horizontal flight. 


\section{PROBLEM STATEMENT}

Roughly speaking, the equations for steady motion of an aircraft's center of mass take the form of:

$0=T-D, \quad 0=-G+L$

where $T$ - thrust developed by the aircraft engines; $D$ - aerodynamic drag resistance of the flowing against the aircraft motion air; $G$ - force of gravity; $L$ - aerodynamic lift.

The second equation of (1) means a "horizontal" flight, i.e. a flight at a constant altitude. The problem to be considered herein may be stated as follows: since the mass of the flying object changes, the lift force has to change correspondingly in order to maintain a stable height. The task, therefore, is to find the extremal as a functional dependence of the speed of the horizontal flight to maintain such horizontal flight maximal duration.

\section{PROPOSED SOLUTION}

Principally simplified mathematical expressions for the components of the equations of (1) are proposed as follows:

$T=-\eta_{T} \frac{d m}{d t}$

where $\eta_{T}$ - coefficient of the proportionality between the engine thrust developed by the aircraft and the rate of the burnt fuel; $m$ - mass of the flying apparatus (aircraft); $t$ - time.

$D=C_{x} \frac{\rho v^{2}}{2} S$

where $C_{X}$ - coefficient of the aerodynamic drag resistance force; $\rho$ - air density at the given altitude; $v$ - speed of the flying object's center of mass; $S$ - characterizing area of the flying object.

And

$G=m g, \quad L=C_{y} \frac{\rho v^{2}}{2} S$,

where $g$ - gravity force acceleration; $C_{y}$ - coefficient of the aerodynamic force of the lift developed by the flying apparatus.

For the coefficient of $\eta_{T}$ from the relation of thrust (2) it is proposed to use the dependence of the form:

$\eta_{T}=\eta \frac{Q}{v}$

where $\eta$ - efficiency (coefficient of the useful action) of the flying apparatus (trialed object) propulsion complex; $Q$ - calorific value of the aviation fuel by its working mass.

Collecting the corresponding members of (2)-(5) into (1), we obtain:

$0=-\eta \frac{Q}{v} \frac{d m}{d t}-C_{x} \frac{\rho v^{2}}{2} S, \quad 0=-m g+C_{y} \frac{\rho v^{2}}{2} S$. 
And

$\eta \frac{Q}{v} \frac{d m}{d t}=-C_{x} \frac{\rho v^{2}}{2} S, \quad m g=C_{y} \frac{\rho v^{2}}{2} S$.

A traditional parabolic equation is proposed to evaluate approximately the dependence for the aerodynamic force coefficients:

$$
C_{x}=C_{x_{0}}+b C_{y}^{2}
$$

where $C_{x_{0}}$ - the value of the coefficient of the aerodynamic drag resistance force $C_{x}$ at the value of the coefficient of the aerodynamic force of the lift developed by the flying object $C_{y}$ when it equals zero; $b$ - a certain value determined at a specified air speeds, for instance, in wind tunnels.

Then:

$$
d t=-\frac{2 \eta Q \rho v S}{C_{x_{0}}\left(S \rho v^{2}\right)^{2}+b(2 m g)^{2}} d m .
$$

The integral of the flight duration will take the form of:

$$
T=-\int_{M_{0}}^{M_{E}} \frac{2 \eta Q \rho \nu S}{C_{x_{0}}\left(S \rho v^{2}\right)^{2}+b(2 m g)^{2}} d m .
$$

where $M_{0}$ - mass of the flying object at the initial moment of time (at the point when the aircraft's "horizontal" flight trajectory begins); $M_{E}$ - mass of the flying apparatus at the end of the active "horizontal" flight fragment.

Now, it is a simple variational problem from the calculus of variations to find the solution to the functional of the integral view (10). The solution (extremal) will be a mathematical expression of the form:

$$
v_{\text {opt }}(m) \text {. }
$$

The extremal (function) (11) can deliver extremal (maximal) value to the objective functional (integral) (10). A necessary condition for the existence of an extremal value of (11) is the satisfaction of the Euler-Lagrange equation:

$$
\frac{\partial F}{\partial v}-\frac{d}{d m}\left(\frac{\partial F}{\partial v_{m}^{\prime}}\right)=0
$$

where $F$ - under-integral function (integrand) of the objective functional (10):

$$
v_{m}^{\prime}=\frac{d v}{d m}
$$


This method of (12), (13) yields:

$v_{\text {opt }}(m)=\sqrt[4]{\frac{4}{3} \frac{b}{C_{x_{0}}}\left(\frac{m g}{S \rho}\right)^{2}}$.

In order to have a time-dependent expression for the optimal fuel mass consumption, from the differential equation of (9):

$\frac{d m}{d t}=-\frac{C_{x_{0}}\left(S \rho v^{2}\right)^{2}+b(2 m g)^{2}}{2 \eta Q \rho v S}$

and with respect to the solution (14), we obtain:

$$
m_{\text {opt }}(t)=\frac{(\eta Q)^{2} \rho S M_{0}}{\left[\eta Q \sqrt{\rho S}+\sqrt[4]{C_{x_{0}}} \sqrt{M_{0}}\left(\frac{4 b g^{2}}{3}\right)^{\frac{3}{4}} t\right]}
$$

One more time-dependent optimal parameter is:

$v_{\text {opt }}(t)$.

This one, (17), can be extracted from the extremal solution (14) by the substitution of mass (16). This yields:

$$
v_{\text {opt }}(t)=\frac{\frac{1}{\sqrt[4]{C_{x_{0}}}} \sqrt[4]{\frac{4 b g^{2}}{3}}}{\sqrt{\frac{\rho S}{M_{0}}}+\frac{\sqrt[4]{C_{x_{0}}}}{\eta Q}\left(\frac{4 b g^{2}}{3}\right)^{\frac{3}{4}} t} .
$$

\section{EXPERIMENTATION (TRIALS ETC.)}

In practice, there may be a problem with determining the aerodynamic coefficients of $C_{x}$ and $C_{y}$ in their dependence upon the angle of attack $\alpha$ in testing before the trial flights, and in coefficient correction after trials. Let us assume the performance characteristics as shown in Fig. 1.

The diagram shown in Fig. 1 serves to illustrate the approach. Numerous such characterizations can be found online, but of course, for the purposes of seeking optimal operation of an aircraft, it is greatly desirable to have the most precise flight trial data. Then, approximation is possible in the following way. 


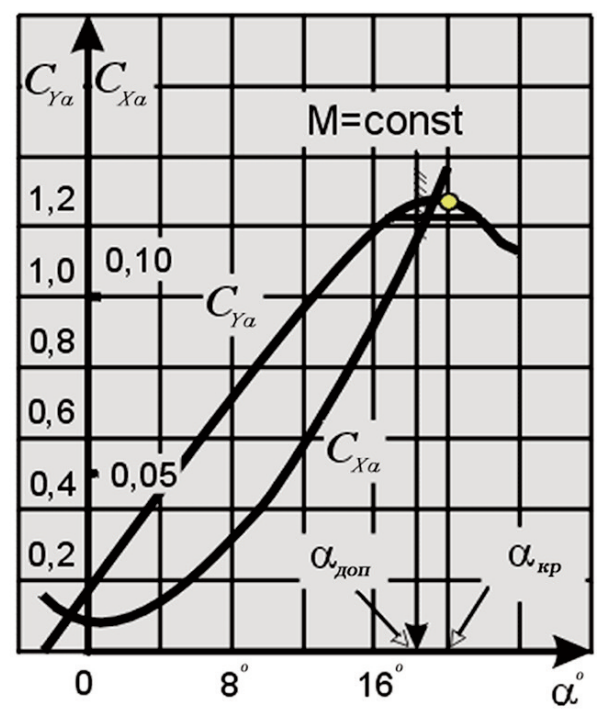

Fig. 1. Dependence of aerodynamic coefficients upon the angle of attack.

\section{For $\mathbf{C}_{\mathbf{y}}$ :}

Fixing a few points of the dependence between $C_{y}$ and $\alpha$, further approximation, for example, by the least-square-roots method or another method, is often applied. If the accuracy is satisfactorily enough, then the methods of (1)-(18) can be implemented.

Here it is proposed to use a two-point conception. This idea is obvious for a quadratic three-member expression:

$$
C_{y}(\alpha)=A \alpha^{2}+B \alpha+C
$$

where $A, B, C$ - as-yet unknown coefficients that are to be determined.

Then, choosing one point at the critical angle of attack $\alpha_{c r}$, which at the example of Fig. 1 is about $\alpha_{c r} \approx 20^{\circ}$, and considering that point as the extremum of the $C_{y}(\alpha)$ function (19) with the aerodynamic coefficient of the lift force value around $C_{y}\left(\alpha_{c r}=20\right)=1.25$, it is possible to pick the other point for approximation at any place on the approximated curve. In the case being considered, let it be $\alpha=-2^{\circ}$ and $C_{y}(\alpha=-2)=0$.

Next step is taking into account that for the extremum conditions at the point of $\alpha_{c r}=20^{\circ}$ and $C_{y}\left(\alpha_{c r}=20\right)=1.25$, the following condition must be satisfied:

$$
\frac{d C_{y}(\alpha)}{d \alpha}=2 A \alpha+B=0
$$

From this, we obtain:

$$
B=-2 A \alpha_{c r} \text {. }
$$


Substituting (21) for its value for (19), this takes the form of:

$C_{y}(\alpha)=A \alpha^{2}-2 A \alpha_{c r} \alpha+C$

Thus, we have obtained the two-point dependence for the approximation:

$C_{y}(\alpha)=A\left(\alpha^{2}-2 \alpha_{c r} \alpha\right)+C$

Now applying vector-matrix method for determining the required coefficients, we obtain:

$\mathbf{C}_{\mathbf{y}}=\left\|\begin{array}{l}1.25 \\ 0\end{array}\right\|, \quad \mathbf{A}=\left\|\begin{array}{cc}20^{2}-\left(2 \cdot \alpha_{c r}\right) \cdot 20^{1} & 20^{0} \\ (-2)^{2}-\left(2 \cdot \alpha_{c r}\right) \cdot(-2)^{1} & (-2)^{0}\end{array}\right\|$.

Here, in (24), $\mathbf{C}_{\mathbf{y}}$ - the vector-column of the aerodynamic coefficient of the lift force $C_{y}(\alpha)$ values; A - the matrix of the angle of attack $\alpha$ values.

In the vector-matrix notation, the system of equations for the unknown coefficients determination of $A$ and $C$ takes the form of:

$\mathbf{C}_{\mathbf{y}}=\mathbf{A} \cdot \mathbf{C}$,

where $\mathbf{C}$ - the vector-column of the unknown coefficients of $A$ and $C$, which are to be determined.

The matrix inverse to the one in $(24)$ is:

$$
\mathbf{A}^{-1}=\left\|\begin{array}{cc}
-2.066 \cdot 10^{-3} & 2.066 \cdot 10^{-3} \\
0.174 & 0.826
\end{array}\right\|
$$

Then from (25) we obtain:

$\mathbf{C}=\mathbf{A}^{-1} \cdot \mathbf{C}_{\mathbf{y}}$

and:

$\mathbf{C}=\left\|\begin{array}{c}-2.604 \cdot 10^{-3} \\ 0.125\end{array}\right\|$

For $\mathbf{C}_{\mathbf{x}}$ :

It is also logical to choose two points, one of which is the extremum at $\alpha_{\min }=1^{\circ}$ and $C_{x}\left(\alpha_{\min }=1\right)=0.01$. The other point, let us select as by the values of $\alpha=20^{\circ}$ and $C_{x}(\alpha=20)=0.14$.

Then following the approach analogous to (19)-(28) gives us:

$\mathbf{C}_{\mathbf{x}}=\left\|\begin{array}{l}0.01 \\ 0.14\end{array}\right\|, \quad \mathbf{A}=\left\|\begin{array}{cc}1^{2}-\left(2 \cdot \alpha_{\min }\right) \cdot 1^{1} & 1^{0} \\ (20)^{2}-\left(2 \cdot \alpha_{\min }\right) \cdot(20)^{1} & (20)^{0}\end{array}\right\|$.

$\mathbf{A}^{-1}=\left\|\begin{array}{cc}-2.77 \cdot 10^{-3} & 2.77 \cdot 10^{-3} \\ 0.997 & 2.77 \cdot 10^{-3}\end{array}\right\|$ 
$\mathbf{C}=\left\|\begin{array}{c}3.601 \cdot 10^{-4} \\ 0.01\end{array}\right\|$.

The diagrams plotted by equations (19)-(31) are shown in Fig. 2.

According to the curves illustrated in Fig. 2, they are very close to those presented in Fig. 1.

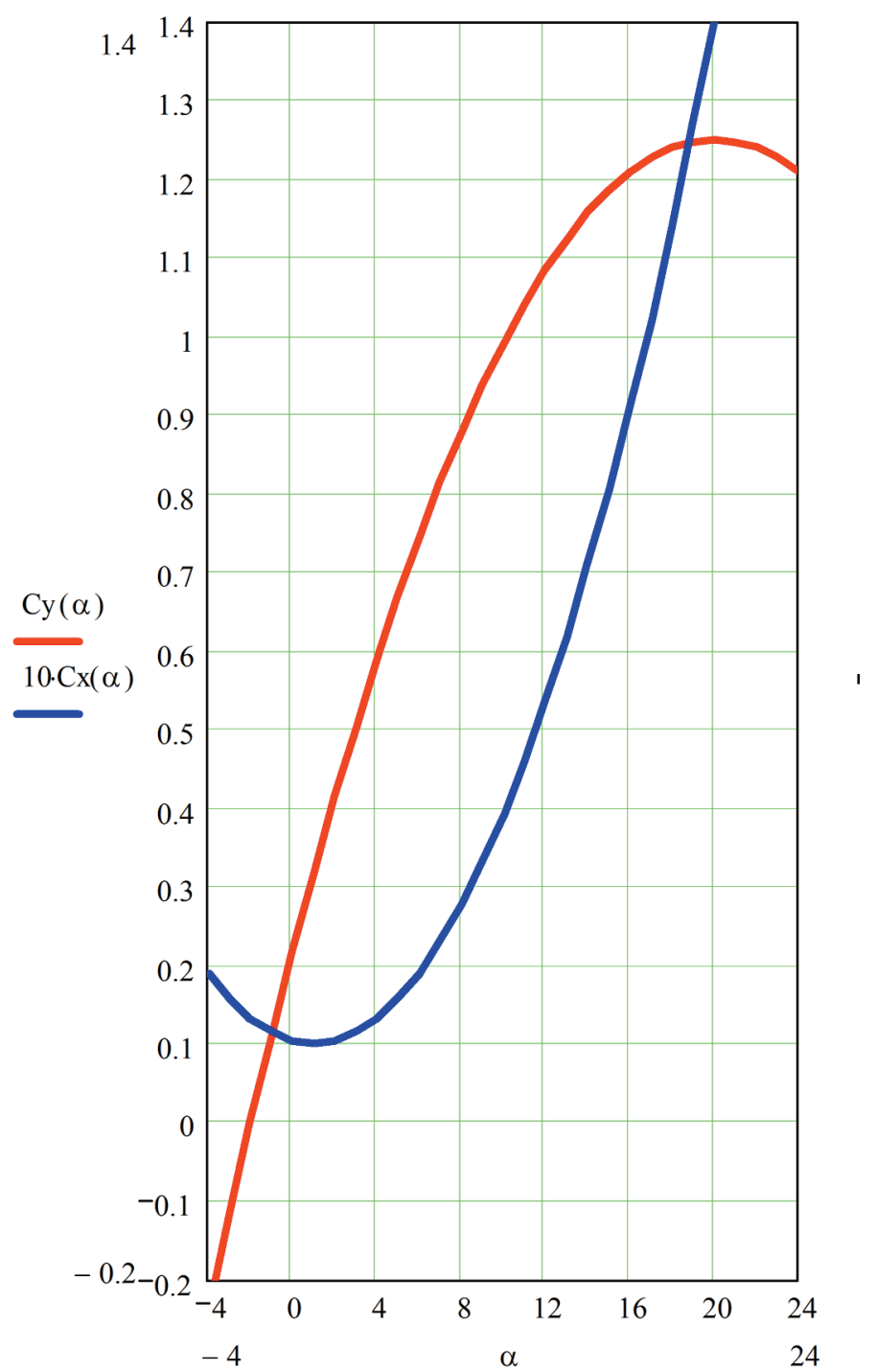

Fig. 2. Approximated dependence of the aerodynamic coefficients upon the angle of attack. 


\section{DISCUSSION}

The proposed approach of (20)-(31) has an advantage over the quadratic three-member expression (19), since when trying to plot a parabolic curve going through three fixed points it is a very hard task to exactly pinpoint the extremum, which symbolizes the destruction of the airflow and which is very important for a stable lift force and safe flight. The same difficulty arises when approximation is conducted with the use of least-square-roots methods. The use of the maximal performance characteristics is the more tangible, with more accuracy in the parameters of the extremal flight models. This may sometimes entail considerable aviation fuel savings. In general, the ideas discussed herein can be implemented to both maximal duration and maximal distance aircraft flights.

\section{CONCLUSION}

The proposed approach allows such important characteristics to be taken into account as the maximal duration or optionally distance of a quasi-horizontal flight. It is recommended to be used in modeling parameters corrected after flight trials. As savings of aviation fuel due to optimal flight performance may provide significant advantages to the aircraft operators, testing of aerodynamic force coefficients must be duly organized, conducted, and monitored; and the parameters themselves must be duly observed, carefully selected, checked, and controlled.

\section{REFERENCES}

[1] Kosmodemyanskiy, A. A., 1965, Kurs teoreticheskoj mekhaniki. Chast' I [Course of Theoretical Mechanics: Part I] (in Russian). Prosvestchenie, Moscow, USSR.

[2] Kosmodemyanskiy, A. A., 1966, Kurs teoreticheskoj mekhaniki. Chast' II [Course of Theoretical Mechanics. Part II] (in Russian), Prosvestchenie, Moscow, USSR.

[3] Kasianov, V., 2013, Subjective entropy of preferences: Subjective analysis, Institute of Aviation, Warsaw, Poland, ISBN 978-83-63539-08-5.

[4] Jaynes, E. T., 1957, "Information theory and statistical mechanics," Physical Review, 106(4), pp. 620-630.

[5] Jaynes, E. T., 1957, "Information theory and statistical mechanics II," Physical Review, 108(2), pp. 171-190.

[6] Jaynes, E. T., 1982, "On the rationale of maximum-entropy methods," Proceedings of the IEEE, Vol. 70, pp. 939-952.

[7] Silberberg, E. and Suen, W., 2001, The Structure of Eeconomics: A mathematical Analysis, McGrawhill, New York, p. 668.

[8] Goncharenko, A. V., 2020, "The ant colony probabilistic model equivalency to the options uncertainty extremized one," Proceedings of the 10th International Conference on Advanced Computer Information Technologies (ACIT'2020), pp. 541-544, Deggendorf, Germany, September 2020.

[9] Goncharenko, A. V., 2020, "Optimal price choice through buyers' preferences entropy," Proceedings of the 10th International Conference on Advanced Computer Information Technologies (ACIT'2020), pp. 537-540, Deggendorf, Germany, September 2020.

[10] Goncharenko, A. V., 2019, "Multi-optional hybridization for UAV maintenance purposes," Proceedings of the IEEE 5th International Conference on Actual Problems of Unmanned Aerial Vehicles Developments (APUAVD), pp. 48-51, IEEE, Kyiv, Ukraine, October 2019.

[11] Goncharenko, A. V., 2019, "Cyber object state maximal probability timing obtained through multioptional technique," Proceedings of the International Workshop on Cyber Hygiene (CybHyg-2019) co-located with 1st International Conference on Cyber Hygiene and Conflict Management in Global 
Information Networks (CyberConf 2019), pp. 132-143, Kyiv, Ukraine, November 2019. http://ceur-ws.org/Vol-2654/.

[12] Goncharenko, A. V., 2018, "Airworthiness support measures analogy to the prospective roundabouts alternatives: theoretical aspects," Journal of Advanced Transportation, Article ID 9370597. doi: $10.1155 / 2018 / 9370597$.

[13] Goncharenko, A. V., 2018, "A multi-optional hybrid functions entropy as a tool for transportation means repair optimal periodicity determination," Aviation, 22(2), pp. 60-66. doi: 10.3846/aviation.2018.5930.

[14] Goncharenko, A. V., 2018, "Development of a theoretical approach to the conditional optimization of aircraft maintenance preference uncertainty," Aviation, 22(2), pp. 40-44. doi: 10.3846/aviation.2018.5929.

[15] Goncharenko, A. V., 2018, "Optimal controlling path determination with the help of hybrid optional functions distributions," Radio Electronics, Computer Science, Control, 1(44), pp. 149158. doi: 10.15588/1607-3274-2018-1-17.

[16] Goncharenko, A. V., 2018, "Aeronautical and aerospace materials and structures damages to failures: theoretical concepts," International Journal of Aerospace Engineering, Article ID 4126085. doi: $10.1155 / 2018 / 4126085$.

[17] Kasjanov, V. and Szafran, K., 2015, "Some hybrid models of subjective analysis in the theory of active systems," Transactions of the Institute of Aviation, 3(240), pp. 27-31. doi: 10.5604/05096669.1194963.

[18] Pąowski Z. T. and Szafran K., 2014, “Ground effect inter-modal fast sea transport," International Journal on Marine Navigation and Safety of Sea Transportation, 8(2), pp. 317-320. doi: 10.12716/1001.08.02.18.

[19] Szafran K., 2014, "Bezpieczeństwo lotu - zasada maksymalnej entropii” [Flight safety - the principle of maximum entropy] (in Polish), Bezpieczeństwo na ladzie, morzu i w powietrzu w XXI wieku, pp. 247-251, ISBN 978-83-61520-02-3.

[20] Szafran, K. and Kramarski, I., 2015, "Safety of navigation on the approaches to the ports of the Republic of Poland on the basis of the radar system on the aerostat platform," International Journal on Marine Navigation and Safety of Sea Transportation, 9(1), pp. 129-134. doi: 10.12716/1001.09.01.16.

[21] Szafran K., 2014, "Bezpieczeństwo operatora pojazdu trakcyjnego - stanowisko prób dynamicznych" [Traction vehicle operator safety - dynamic test station] (in Polish), Logistyka, 6, pp. 192-197.

[22] Krzysztofik, I. and Koruba, Z., 2014, "Mathematical model of movement of the observation and tracking head of an unmanned aerial vehicle performing ground target search and tracking," Journal of Applied Mathematics, Special Issue (2014). doi: 10.1155/2014/934250.

[23] Hulek D. and Novák M., 2019, "Expediency analysis of unmanned aircraft systems," in Proceedings of the 23rd International Conference on Transport Means, pp. 959-962, Palanga, Lithuania, 2019.

[24] Patel G. C. M., Chate G. R., Parappagoudar M. B., and Gupta K., 2020, "Intelligent modelling of hard materials machining," Springer Briefs in Applied Sciences and Technology, pp. 73-102.

[25] Béjar S. M., Vilches F. J. T., Gamboa C. B., and Hurtado L. S., 2020, "Fatigue behavior parametric analysis of dry machined UNS A97075 aluminum alloy," Metals, 10(5), pp. 631-102.

[26] Béjar S. M., Vilches F. J. T., Gamboa C. B., and Hurtado L. S., 2020, "Cutting speed and feed influence on surface microhardness of dry-turned UNS A97075-T6 alloy," Applied Sciences (Switzerland), 10(3), pp. 1049-102.

[27] Piskunov, N. S., 1985, Differentsiyal'noye i integral'noye ischisleniya dla vtuzov [Differential and Integral Calculus for Higher Engineering Educational Institutions] (in Russian), vol. 2: 13th edition. Nauka, Moscow, USSR. 


\title{
METODA DWUPUNKTOWEJ \\ APROKSYMACJI DO WYZNACZANIA WSPÓŁCZYNNIKÓW SIŁ AERODYNAMICZNYCH DLA LOTÓW HORYZONTALNYCH O MAKSYMALNYM CZASIE TRWANIA
}

\begin{abstract}
Abstrakt
W pracy zaproponowano metodę dwupunktowej aproksymacji do wyznaczania współczynników sił aerodynamicznych samolotu i porównano ją z metodami tradycyjnymi. Koncepcja wariacyjna jest wykorzystywana do prowadzenia prób w locie samolotu dla maksymalnego czasu trwania lotów quasihoryzontalnych. Przedstawiono zalety opisanych teorii optymalizacyjnych w aspekcie oszczędności paliwa lotniczego. Przedstawiono wyniki przykładu numerycznego.
\end{abstract}

Słowa kluczowe: siła aerodynamiczna, współczynnik aerodynamiczny, test, próba, statek powietrzny, maksymalny czas trwania, maksymalny dystans, lot, lot horyzontalny 